\title{
Psychological aspects of diencephalotomy
}

\author{
M. F. JURKO AND O. J. ANDY
}

\author{
From the Department of Neurosurgery, University of Mississippi Medical Centre, Jackson, \\ Mississippi, U.S.A.
}

The short- and long-term effects of surgery of the basal ganglia on behaviour have received relatively little attention. In previous studies emphasis has been on the more immediate post-operative changes for evaluating the effects of surgical lesions on intellectual and perceptual functions. With respect to intelligence only one aspect, intelligence quotient (I.Q.), was emphasized. The objectives in this study were to evaluate several aspects of intelligence and simple perception for relatively longer post-operative periods.

\section{METHOD}

PATIENTS This study was done on 25 patients (10 men and 15 women). Mean age was $54 \cdot 2$ years (range $40-70$ years); mean educational level 13.8 years; mean duration of illness 5.4 years (range 1-10 years). The patients all showed some degree of generalized Parkinson involvement. The chief complaints ranged from moderate and unilateral to quite severe and bilateral tremor and rigidity. All patients were right-handed, i.e., left brain dominant.

SURGERY Unilateral brain lesions were made under local anaesthesia. A 20-gauge barrel electrode with a 4 to $10 \mathrm{~mm}$. non-insulated tip was inserted into the diencephalon through a frontal burr hole (Andy, 1959). The sites of coagulation were primarily in the posterior ventral thalamus-subthalamic region (Andy, Jurko, and Sias, 1963). The stereotactic atlas of Schaltenbrand and Bailey (1959) was used to determine placing of the electrodes.

PSYCHOLOGICAL TEST SCHEDULE The test used to evaluate intellectual functioning were the verbal portion of the Wechsler adult intelligence scale (Wechsler, 1955) and a visual-motor performance group consisting of the Bender-Gestalt (Bender, 1946); memory-for-designs (Graham and Kendall, 1960); and trail-making (Reitan, 1956) tests. Simple perception was followed with a group consisting of the spiral aftereffect ${ }^{1}$ (Freeman and Josey, 1949); depth perception ${ }^{2}$; two-point discrimination ${ }^{3}$; and the memory-for-designs test oriented to evaluate perception. Testing was done during a two-day period at the

'Spiral Aftereffect Apparatus, Psychological Research and Development Corp., Tampa, Florida.

${ }^{2}$ Apparatus No. 702, Lafayette Instrument Co., Lafayette, Indiana.

${ }^{3}$ Two-point aesthesiomenter (Weinstein Two-Point Type), Shaw Laboratories, Inc., Syosset Island, New York. tollowing intervals: one week pre-operatively; five day post-operatively; two months post-operatively; six to eight months post-operatively; and one and a half to tw. years post-operatively. All patients were tested through out the study by the same examiner.

EVALUATION OF DATA Since the Wechsler adult intelli: gence scale is a test which gives well-defined numericat scores continuously distributed, mean scores could bey obtained and appropriately compared pre- and poste. operatively with the parametric $t$ test. However, the tes in the visual-motor performance and the simple percep tion groups present scoring difficulties. Tests like thes Bender-Gestalt are commonly evaluated by clinicap judgment and there is no widely accepted methoduo? numerical evaluation. Observations like those made $\bar{g}_{0}{ }_{P}$ linear deviation in the memory-for-designs test are 98 difficult to present in numerical scores. For tests trail making the standardized scoring is dependent ugop the patient's ability easily to execute motor movements and do require modification when used on the Parkingo patient. The spiral aftereffect has such a limited sprea scores that it is usually evaluated in terms of a cus of

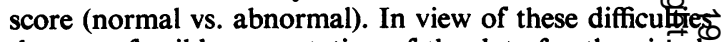
the most feasible presentation of the data for the visiab motor performance and simple perception groups appeared to be reduction to categorized form. Though th type of evaluation does not permit the use of the more exacting statistical methods possible with mean score it avoids a deceptive aura of mathematical rigour nom inherent in these types of tests. Since pre-operativo performance was near optimum and in only isolate instances was there a better score post-operatively, the follow-up data was dichotomized into impairment and non-impairment categories. The impairment categor represented the extremes of poor performance based on criteria which pre-operatively were well within thephysical and mental capabilities of the patients. The following section describes the method of evaluating impaired performance for each test in the visual-motor performance and simple perception groups. The number of patients in the impaired and the non-impaired categor was compared with the ron-parametric binomial ex pansion test.

BENDER-GESTALT These are free-hand reproduction with the test cards placed before the subjects. Impaire performance was scored if two of the following four werel present: (1) deterioration in the form of the figures, (2) 
reversals of figures, (3) perseveration of design, and (4) marked crowding or expansion in placement of the figures. An example of expansion is demonstrated in Figure 1. The same patient displayed perseveration. He continued to draw the three rows of open circles on the desk, beyond the limits of the paper. Note that two months postoperatively both expansion and perseveration were not present.

MEMORY-FOR-DESIGNS The task consisted of drawing designs from memory after a five-second exposure. The test is scored on total number of errors. Errors were not more than four for the pre-operative group. Postoperatively eight errors or more was considered an inpaired performance.

TRAIL MAKING This test is a paper-pencil maze consisting of two parts. Part A has the less difficult all-number pathway and part $B$ the more difficult alternating numberletter pathway. Post-operative impairment was the inability to perform part B.

SPIRAL AFTEREFFECT This is a test of apparent (illusory) motion. When rotation of the spiral ceases the normal response is one of apparent movement of the spiral in the opposite direction. The maximum score in our use of the test, after Blau and Schaffer (1960), was 8 points representing four clock-wise and four counterclockwise trials. All patients pre-operatively had a score of 6 or better. Because of the stability of the illusion in most subjects over time, a score of 5 or less was treated as impairment in performance (failure of the test). This cut- off score is also in accord with the findings of Blau and Schaffer (1960) in which a score of zero through 5 was shown to be a highly predictive abnormal.

MEMORY-FOR-DESIGNS This test was used in our test battery to evaluate intellectual function after diencephalotomy with a minor alteration in instructions to indicate changes in perception. The subject was required to draw each figure from memory after a five-second exposure. He was asked to place the figures in columns down the page rather than across the sheet as is usually done. The test was scored for the presence of obvious linear deviation of the columns to the left or right. Note the marked deviation to the left five days post-operatively (Fig. 2).

DEPTH PERCEPTION In the performance of the test the subject aligned two rods suspended in an illuminated box devoid of cues. Twenty randomized trials were given, 10 trials with a $3 \mathrm{~cm}$. misalignment and 10 trials with a $7 \mathrm{~cm}$. misalignment. Impaired depth perception was scored when there was a decrease of one-third or more in both of the distances compared with pre-operative skill.

TWO-POINT DISCRIMINATION The threshold was tested for two areas of both hands, the thenar and hypothenar eminences. Four descending trials (starting with a separation that was easily discriminated and gradually reduced) and four ascending trials (starting with a separation that was not discriminated and gradually increased) were randomly given and averaged. Pre-operative thresholds ranged from a 6 to $18 \mathrm{~mm}$. separation. Post-operative

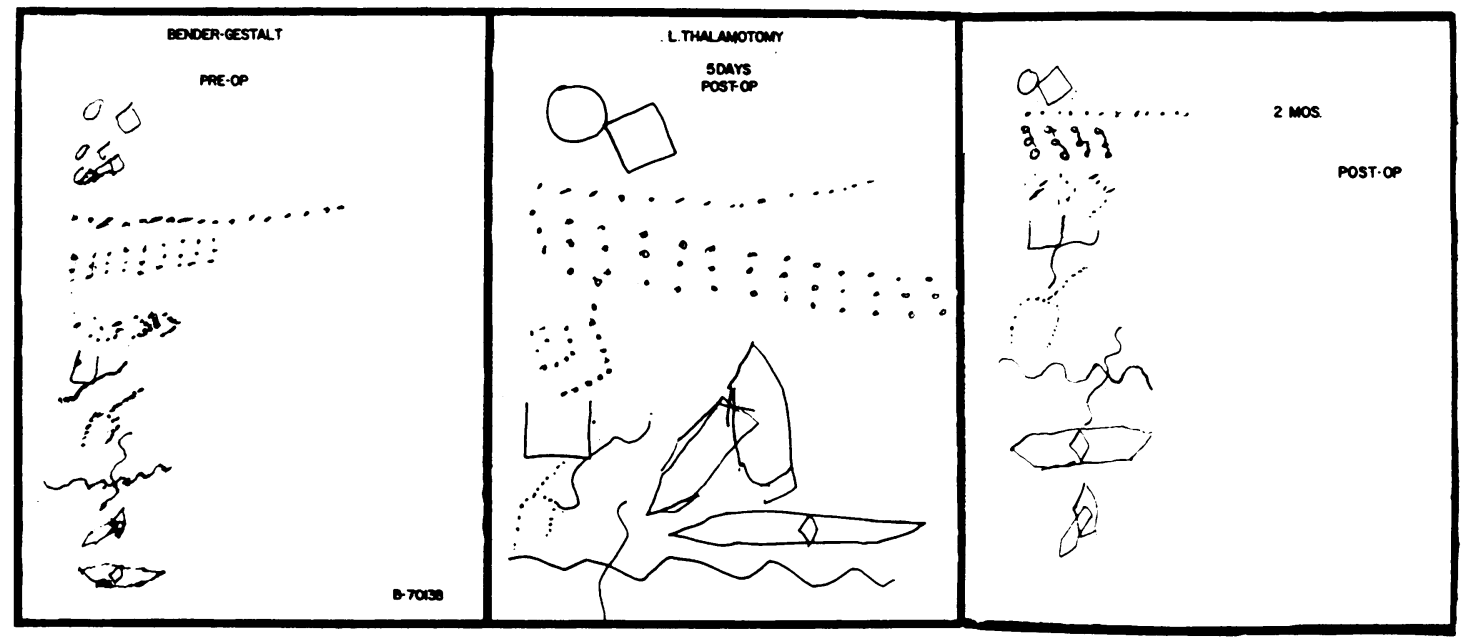

FIG. 1. Pre-operative and post-operative (five days and two months) Bender-Gestalt protocols.

Note the marked tremor in the pre-operative drawings and the absence of tremor after surgery. The small size of the pre-operative figures relative to post-operative size can be accounted for, in part, by restrictions imposed by the motor disorder. Note that five days post-operatively, perseveration is evident in the drawing of the three rows of open circles. The patient continued to draw more open circles on the desk beyond the limits of the paper. Also, the same three rows of open circles are erroneously connected by vertical lines in the pre-operative and again in the post-operative drawings two months later. This visual defect was not present in the post-operative period of five days. 


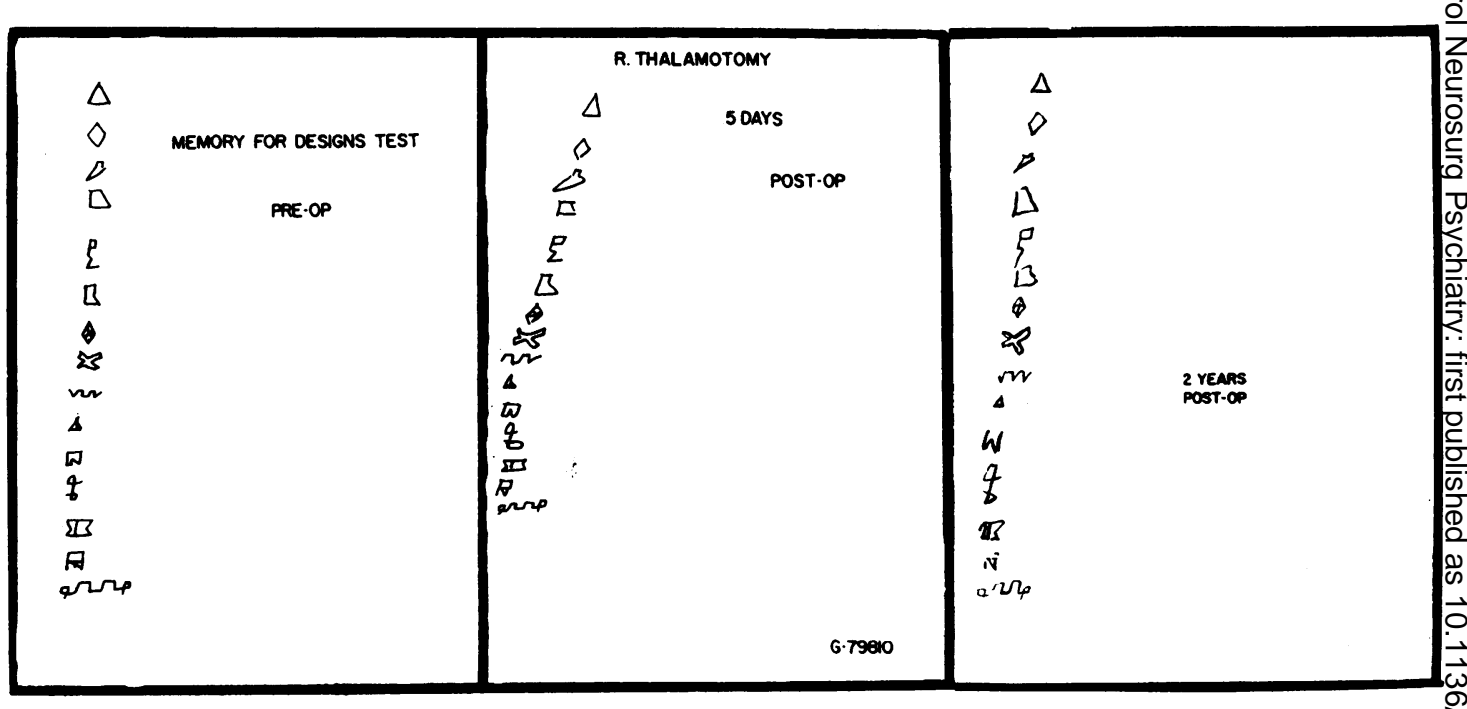

FIG. 2. Memory-for-designs test modified to evaluate linear deviation as a test of perception. Note the extreme deviatio to the left five days post-operatively which tends to persist two years later.

impairment of sensitivity was scored if there was an increase in point separation of $5 \mathrm{~mm}$. or greater for both test areas.

\section{RESULTS}

INTELLECTUAL FUNCTIONS A decrease in verbal I.Q. was apparent in the testing interval of one and a half to two years (mean decrement, 10 points). This represents a loss of 8 to 14 points in six out of eight patients $(75 \%$ of the subjects). In contrast, there was no significant change in the acute postoperative period (five days) nor in the testing intervals of two months and six to eight months. The verbal I.Q. and the subtests comprising the Wechsler adult intelligence scale, which reveal significant or relatively consistent increased or decreased trends, are given in Table $I$. It is to be noted that the decrease in

TABLE I

PRE- AND POST-OPERATIVE WECHSLER VERBAI. I.Q. SCORES

\begin{tabular}{|c|c|c|c|c|c|}
\hline \multirow[t]{2}{*}{ Time of Test } & \multirow[t]{2}{*}{$\begin{array}{l}\text { No. of } \\
\text { Patients }\end{array}$} & \multicolumn{3}{|c|}{ Subtests (scaled score) ${ }^{1}$} & \multirow[t]{2}{*}{$\begin{array}{l}\text { Verbal } \\
\text { I.Q. }\end{array}$} \\
\hline & & $\begin{array}{l}\text { Digit } \\
\text { Span }\end{array}$ & $\begin{array}{l}\text { Similari- } \\
\text { ties }\end{array}$ & $\begin{array}{l}\text { Compre- } \\
\text { hension }\end{array}$ & \\
\hline $\begin{array}{l}\text { Pre-operatively } \\
\text { Post-operatively }\end{array}$ & 25 & $10 \cdot 0$ & $19 \cdot 6$ & $24 \cdot 6$ & 114 \\
\hline $\begin{array}{l}5 \text { days } \\
2 \text { mth. } \\
6-8 \text { mth. } \\
1 \frac{1}{2}-2 \text { yr. }\end{array}$ & $\begin{array}{r}21 \\
14 \\
13 \\
8\end{array}$ & $\begin{array}{l}10.9 \\
11 \cdot 1 \\
10.9 \\
10.4\end{array}$ & $\begin{array}{l}18 \cdot 6 \\
17 \cdot 1 \\
16 \cdot 0 \\
12 \cdot 2^{2}\end{array}$ & $\begin{array}{l}23 \cdot 2 \\
24 \cdot 3 \\
23 \cdot 2 \\
22 \cdot 2\end{array}$ & $\begin{array}{l}110 \\
114 \\
112 \\
104^{2}\end{array}$ \\
\hline
\end{tabular}

${ }^{1}$ The remaining subtest (information, arithmetic, and vocabulary) showed no consistent trends.

'Significant at 0.05 level ( $t$ test). verbal I.Q. was mainly due to poor performance irip one subtest, similarities. The similarities subtes evaluates abstract thinking by requiring the subfor? to discriminate between essential and superfigat likenesses. No statistically significant changes wire present in the remaining subtests. The comprehend sion subtest, which depends on the possession of $\$$ certain amount of practical information and a genefip ability to evaluate past experience, showed liftele decline. On the other hand, performance in do span, a test of attention and retentiveness, was cono sistently higher post-operatively. This was thought to reflect the effect of practice. The remaining subఠ tests-information, arithmetic, and vocabularyshowed no significant changes.

Unlike the I.Q., which showed little change earlyơ⿱ post-operatively, maximal decrement in all of the visual-motor performance tests occurred in th $\overrightarrow{\vec{E}}$ acute (five days) post-operative period (Table II) Greatest impairment was in the Bender-Gesta度

\section{TABLE II}

NUMBER OF PATIENTS WITH POST-OPERATIVE IMPAIRMEN IN VISUAL-MOTOR PERFORMANCE TESTS OVER A TWO-YEA

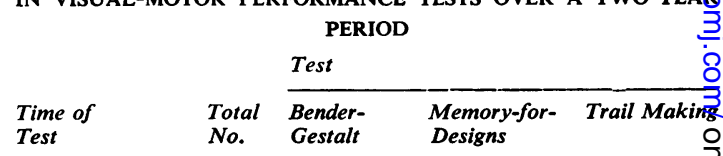

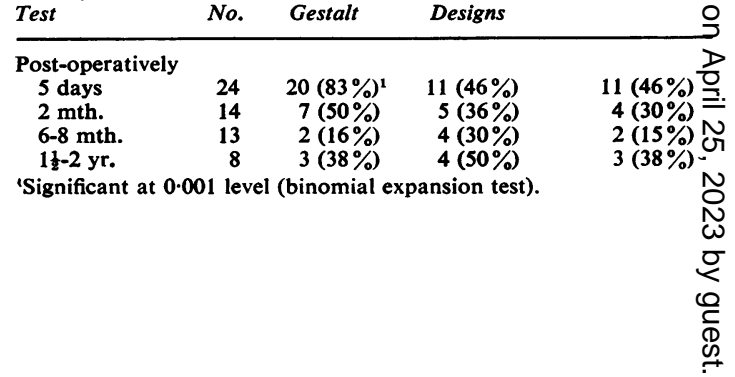


test. Evidence of continuing impairment, one and a half to two years post-operatively, was seen for all of the tests. In the trail-making and memory-fordesigns tests, subjects with left brain operations appeared to be more frequently impaired than those with right brain lesions (Table III). Though this trend did not reach the level ( $p=0.05$ or better) usually taken as significant for our small sample, it is suggestive of a laterality difference and should be pursued in a larger sample.

TABLE III

IMPAIRED VISUAL-MOTOR PERFORMANCE RELATED TO LATERALITY OF BRAIN LESIONS FIVE DAYS POST-OPERATIVELY

\begin{tabular}{lcc} 
Test & $\begin{array}{c}\text { Left Operation } \\
\text { (12 patients) }\end{array}$ & $\begin{array}{l}\text { Right Operation } \\
(12 \text { patients) }\end{array}$ \\
\hline Trail-making & $8(67 \%)^{1}$ & $3(25 \%)$ \\
Memory-for-designs & $7(60 \%)$ & $4(33 \%)$ \\
Bender-Gestalt & $11(90 \%)$ & $9(75 \%)$ \\
'Significant at 0.10 level (Chi-square test). &
\end{tabular}

SIMPLE PERCEPTION There was impairment in all of the simple perception tests in the acute (five days) period (Table IV). The greatest declines were in depth perception and two-point discrimination tests, with decrement present in over $50 \%$ of the patients.

\section{TABLE IV}

NUMBER OF PATIENTS WITH POST-OPERATIVE IMPAIRMENT IN SIMPLE PERCEPTION TESTS OVER A TWO-YEAR PERIOD

\begin{tabular}{|c|c|c|c|c|c|}
\hline \multirow[b]{2}{*}{$\begin{array}{l}\text { Time of } \\
\text { Test }\end{array}$} & \multirow[b]{2}{*}{$\begin{array}{l}\text { Total } \\
\text { No. }\end{array}$} & \multicolumn{4}{|l|}{ Test } \\
\hline & & $\begin{array}{l}\text { Spiral } \\
\text { After- } \\
\text { effect }\end{array}$ & $\begin{array}{l}\text { Linear } \\
\text { Deviation } \\
(M F D)\end{array}$ & $\begin{array}{l}\text { Depth } \\
\text { Perception }\end{array}$ & $\begin{array}{l}\text { Two-point } \\
\text { Discrimina } \\
\text { tion }\end{array}$ \\
\hline
\end{tabular}

Post-

operatively

$\begin{array}{lrlrll}5 \text { days } & 24 & 10(42 \%) & 10(42 \%) & 15(75 \%)^{1}, 2 & 12(60 \%)^{1} \\ 2 \text { mth. } & 14 & 2(14 \%) & 4(30 \%) & 2(14 \%) & 5(36 \%) \\ 6-8 \text { mth. } & 13 & 0 & 4(30 \%) & 1(7 \%) & 2(15 \%) \\ 1 \frac{1}{2}-2 \text { yr. } & 8 & 0 & 2(25 \%) & 0 & 1(13 \%)\end{array}$

$2(25 \%) \quad 0 \quad 1(13 \%)$

'Based on 20 patients.

${ }^{2}$ Significant at $\mathbf{0 . 0 2}$ level (binomial expansion test);

${ }^{3}$ Significant at 0.06 level.

Two-point discrimination remained impaired in a significant number of subjects two months postoperatively, and there was continuing deficit in one patient two years after surgery. Among the 12 patients with decrement in two-point discrimination, six had contralateral decrement, three had ipsilateral, and three had bilateral. Two of the three patients with ipsilateral deficits were operated on the left brain. Linear deviation also gave evidence of long-range impairment. Figure 2 illustrates extreme deviation to the left five days post-operatively and deviation still apparent two years later. There was a trend for a greater number of subjects oper-
TABLE V

IMPAIRED SIMPLE PERCEPTION RELATED TO LATERALITY OF BRAIN LESIONS FIVE DAYS POST-OPERATIVELY

\begin{tabular}{lcc} 
Test & $\begin{array}{l}\text { Left Operation } \\
(12 \text { patients })\end{array}$ & $\begin{array}{l}\text { Right Operation } \\
(12 \text { patients })\end{array}$ \\
\hline Spiral after-effect & $3(25 \%)$ & $7(60 \%)$ \\
Linear deviation & $6(50 \%)$ & $4(33 \%)$ \\
Depth perception & $(8$ patients) & $(12$ patients $)$ \\
Two-point discrimination & $3(38 \%)$ & $10(83 \%)^{1}$ \\
& $3(38 \%)$ & $9(70 \%)$
\end{tabular}

${ }^{1}$ Significant at $0 \cdot 10$ level (Chi-square test).

ated on the right brain to show impaired simple perception than those operated (Table V) on the left brain.

\section{COMMENT}

Riklan, Diller, Weiner, and Cooper (1960) reported significant impairment in the Wechsler verbal I.Q. in the 'immediate' ( 8 to 43 days) post-operative period. In the 'long-range' period (4 to 13 months) there was no significant difference compared with postoperative performance. Our patients, in contrast, showed no impairment in the Wechsler verbal I.Q. immediately post-operatively. Deficit was only found one and a half to two years after operation. Furthermore, the decrement was due to a decline in one specific subtest, similarities. It should be noted that in the series of Riklan et al. (1960) patients represent a mixture of chemothalamotomy and chemopallidotomy testable 'usually between two and four weeks subsequent to surgery depending upon the clinical condition of the patient.' This implies that the post-operative morbidity was pronounced in some patients which may account for the early impairment, especially in those who could not be tested within five days after surgery. The technique utilized in our study consisted of electrolysis of diencephalic structures and 21 out of 25 patients could be so tested within five days after surgery. In addition, our long-range testing period was 18 to 24 months in contrast to theirs which was four to 13 months.

Our observations of delayed impairment in verbal I.Q. are in accord with a recent case report by Watkins and Oppenheimer (1962). They described late decline in the Wechsler-Bellevue intelligence scale after an apparently good recovery from unilateral chemothalamotomy. The Wechsler verbal I.Q. was 114 pre-operatively, 100 at one month post-operatively, 109 at five months, and 98 at 18 months. No information was given on their subtest scores. It is of interest to note that studies in lobotomy patients also revealed decrements which were specific for only some Wechsler subtests (de 
Mille, 1962; Smith and Kinder, 1959). In addition, the changes were not present immediately after surgery, but became evident eight years later (Smith and Kinder, 1959).

The question arises as to whether the delayed postoperative decrement in the (Wechsler) verbal I.Q. can be attributed to deterioration associated with Parkinsonism. Riklan et al. (1960) reported no significant change in Wechsler I.Q. scores in their unoperated Parkinson patients in a mean testretest of nine months. Machover (1957) used the Rorschach test to evaluate intellectual function in two groups of Parkinson patients, each representing a relatively short and long period of illness. A comparison of the short duration group (mean, 2.5 years) with the long duration group (mean, 19.6 years) showed 'no really significant difference in degree or kind of impairment in cognitive integrity or efficiency'. In view of these observations, it would appear unlikely that the long-term impairment found in our study is due to the natural course of Parkinson's disease. In contrast to the lack of impairment in verbal I.Q. immediately after surgery, maximal decrement in the visual-motor performance tests occurred in the acute period after operation. These skills obviously implicate a different aspect of intellectual function than the Wechsler I.Q.

There are many reports of impairment in perception following cortical lesions but only a few following subcortical lesions. In a recent study Proctor, Riklan, Cooper, and Teuber (1963) reported decrement in two-point discrimination and punctuate pressure thresholds immediately after chemothalamotomy. Significantly higher thresholds for punctuate pressure were still evident five months postoperatively. These findings parallel our observations of maximal number of patients showing decrement in somesthesis in the acute (five days) period following diencephalotomy. There was little long-range deficit; only one patient still had impairment one and a half years post-operatively. It should be noted that Teuber (1962) found decrement in two-point discrimination 10 years after penetrating missile wounds of the cortex. The above investigators also found that impairment was greatest contralateral to the lesion and ipsilateral impairment was more frequent in the group with lesions of the left brain. Our observations on diencephalic lesions are in accord with those findings.

Two-point discrimination and depth perception tests showed impairment in more patients after diencephalic lesions than did spiral aftereffect and linear deviation tests. It is of interest that the former tests are to a large degree tactile-spatial in contrast to the latter which are visual-spatial. This difference may be due to the greater involvement of the primary sensory relay nuclei of the thalamus consequent to $\bar{Z}$ the diencephalic lesions. It must also be noted that the impaired perception was not accompanied byo general intellectual deficit. Disturbed perceptione without involvement of general intellect has also $\sigma^{\circ}$ been reported by Denny-Brown, Meyer, and Horen-en stein (1952), Gerstmann (1958), and others.

The laterality of the lesion appears to affecto intelligence and simple perception differentially. This $\vec{z}$ is now quite well documented for cortical represen $\Rightarrow$ tation but has received little attention in relation to diencephalic function. Greater impairment of simple perception appeared among our patients with righe subcortical operations. Recently Piercy, Hécaen $\frac{\bar{s}}{5}$ and Ajuriaguerra (1960) reported on 67 patients whoळ had constructional apraxia associated with unilateraps cerebral lesions. The deficit was measured by having. the patients draw a house and a cube. They concluded 'that, in general, constructional apraxia associated $\overrightarrow{\vec{t}}$ with right hemisphere lesions involves greater impairment of perceptual functions than is the case in the left hemisphere syndrome'. In contrast to simple perception, impairment of intelligence was morey frequent among our patients with left diencephalico lesions. This is in accord with laterality effects noted on patients with cortical lesions. Reitan (195) in a carefully controlled study of 14 patients whip surgical verification of pathology, found impaind

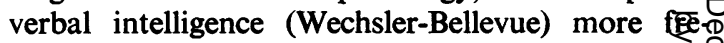
quently in patients with left-side cortical lesions. $\overparen{\Phi}$

SUMMARY

Intellectual function and simple perception were evaluated before and during a two-year period aftere placement of lesions in the diencephalon of 250 Parkinson patients.

Psychological tests employed were verbal I.Q $\frac{\mathscr{Q}}{\not}$ (Wechsler) and visual-motor tests: Bender-Gestalt 0 memory-for-designs, and trail-making tests. Tests of perception consisted of spiral aftereffect, memory for-designs, depth perception, and two-point dis crimination threshold.

Immediate impairment was verified in all the testș comprising the motor performance battery, anळ recovery was present within six months. However the verbal I.Q. was not immediately impaired.

Delayed impairment of verbal I.Q. appeareक one and a half to two years post-operatively. It should be noted that the decrement was confined to one subtest only, similarities (a test of abstract thinking).

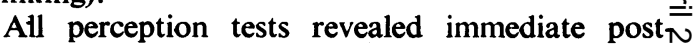
operative impairment. Only one (linear deviation) ${ }^{\mathrm{r}}$ showed decrement at two years. 
Right diencephalic lesions produced greater impairment of simple perception and left diencephalic lesions produced greater impairment of intellectual function.

\section{REFERENCES}

Andy, O. J. (1959). Globus pallidus coagulation technique. Surg. Forum, 1958, 9, 698-700.

-, Jurko, M. F., and Sias, F. R. Jr. (1963). Subthalamotomy in treatment of Parkinsonian tremor. J. Neurosurg., 20, 860-870.

Bender, L. (1946). Bender Visual Motor Gestalt Plates. Amer. Orthopsychiatric Ass. Inc., New York.

Blau, T. H., and Schaffer. R. E. (1960). The spiral aftereffect test (SAET) as a predictor of normal and abnormal electroencephalographic records in children. J. con. Psychol., 24, 35-42.

de Mille, R. (1962). Intellect after lobotomy in schizophrenia: A factor-analytic study. Psychol. Monogr., 76, No. 16, pp. 1-18. [Whole No. 535].

Denny-Brown, D., Meyer, J. S., and Horenstein, S. (1952). The significance of perceptual rivalry resulting from parietal lesion. Brain, 75, 433-471.

Freeman, E., and Josey, W. E. (1949). Quantitative visual index to memory impairment. A preliminary report. Arch. .Neurol. (Chic.), 62, 794-797.

Gerstmann, J. (1958). Psychological and phenomenological aspects of disorders of the body image. J. nerv. ment. Dis., 126, 499-512.

Graham, F., and Kendall, B. (1960). Memory for Designs Plates. Psychological Test Specialists, Missoula, Montana.
Machover. S. (1957). Rorschach study on the nature and origin of common factors in the personalities of Parkinsonians. Psychosom. Med., 19, 332-338.

Piercy, M., Hécaen, H., and De Ajuriaguerra, J. (1960). Constructional apraxia associated with unilateral cerebral lesions-left and right sided cases compared. Brain, 83, 225-242.

Proctor, F., Riklan, M., Cooper, I. S., and Teuber, H. (1963). Somatosensory status of Parkinsonian patients before and after chemothalamectomy. Neurology (Minneap.), 13, 906-912.

Reitan, R. M. (1955). Certain differential effects of left and right cerebral lesions in human adults. J. comp. physiol. Psychol., 48. 474-477.

(1956). Trail Making. Mimeographed. Indiana University Medical Center, Indianapolis.

Riklan, M., Diller, L., Weiner, H., and Cooper, I. S. (1960). Psychological studies on effects of chemosurgery of the basal ganglia in Parkinsonism. Arch. gen. Psychiat., 2, 22-32.

Schaltenbrand, G., and Bailey, P. (1959). Introduction to Stereotaxis, with an Atlas of the Human Brain. Grune and Stratton, New York.

Smith, A., and Kinder, E. F. (1959). Changes in psychological test performances of brain-operated schizophrenics after 8 years. Science, 129, 149-150.

Teuber, H. L. (1962). Effects of brain wounds implicating right or left hemisphere in man: Hemisphere differences and hemisphere interaction in vision, audition, and somesthesis. In International Symposium on Cerebral Dominance, edited by Vernon B. Mountcastle, pp. 131-157. Johns Hopkins University Press, Baltimore.

Watkins, E. S., and Oppenheimer, D. R. (1962). Mental disturbances after thalamolysis. J. Neurol. Neurosurg. Psychiat., 25, 243-250. Wechsler, D. (1955). WAIS. Psychological Corporation, New York. 